\title{
Evaluation of body-mapping shirts design for activities in warm environments
}

\author{
Li-Yen Lin ${ }^{1 *}$, Simon Annaheim², Psikuta Agnieszka², Faming Wang², Li-Chu Wang ${ }^{1}$, Robert Jou ${ }^{3}$, Sheng-fu Chiu', \\ René Rossi ${ }^{2}$
}

From 15th International Conference on Environmental Ergonomics (ICEE XV)

Portsmouth, UK. 28 June - 3 July 2015

\section{Introduction}

The aim of this study is to explore the fundamental knowledge of design high performance body mapping t-shirts(BMT) for warm environments. Several factors were discussed including physical properties of fabrics, fitness of the t-shirts and comparing body-mapping versus traditional non-body mapping $\mathrm{t}$-shirts.

\section{Methods}

Five textile materials, including modified hydrophilic nylon(No1), moisture management fabric(No2), porous structure mesh fabric(No3), highly wicking knitted fabric (No4), single jersey with cooling printing(No5) were selected for this study and also a commercial bodymapping shirt was chosen as the control sample. The physical properties of the five selected fabrics were determined, i.e., thermal insulation, evaporative resistance, thickness and moisture management properties. The heat and mass transport and thermo-physiological impact of the samples were assessed by using a sweating torso and a thermal human simulator (THS). The thermal parameters were predicted during a two-hour exposure in $20{ }^{\circ} \mathrm{C}$ and $28{ }^{\circ} \mathrm{C}$ at 6 METs. Two of the studied fabrics were chosen to design BMT by locating to different clothing parts. The effect of clothing fit on the local heat exchange of BMT was examined as well. The BMT were sewn made-to-measure in two different designs, tight fit and regular fit. The thermal and evaporative properties of BMT were evaluated by using the manikin. Two phases were applied, dry heat loss was obtained from the first phase and a sweat amount of $110 \mathrm{~g} \cdot \mathrm{h}^{-1}$ was applied to obtain wet heat loss during the second phase, where

\footnotetext{
* Correspondence: Iylin.0881@ttri.org.tw

'Department of Testing and Certification, Taiwan Textile Research Institute, New Taipei City, Taiwan

Full list of author information is available at the end of the article
}

heating power in the individual zones was recorded to maintain surface temperature of manikin at $34{ }^{\circ} \mathrm{C}$.

\section{Results}

The initial cooling rate(IC) of the five selected fabrics were in the range of $5{ }^{\circ} \mathrm{C} \cdot \mathrm{h}^{-1}-13{ }^{\circ} \mathrm{C} \cdot \mathrm{h}^{-1}$, and the sustained cooling(SC) were in the range of $0.5^{\circ} \mathrm{C} . \mathrm{h}^{-1}-1.3^{\circ} \mathrm{C} . \mathrm{h}^{-1}$. Dry and wet heat loss from the trunk of manikin for tight fitting shirt designs were both $15 \%$ higher than the regular ones.

\section{Discussion}

Fabric sample-No3 showed an increased IC, while SC was better for fabric sample-No1. Dry heat loss from the trunk of manikin revealed an obvious difference $(\mathrm{P}<0.001)$ between regular and tight fitting shirt designs. The effect of fitting was confirmed in case of wet heat loss as well. Highest wet and evaporative heat loss and therefore best overall cooling was found for the body mapping shirt with fabric sample-No1 in the upper trunk (chest and shoulders) and fabric sampleNo3 in the lower trunk (abdomen and lower back).

\section{Conclusion}

Fabric sample-No1 showed the best performance in chest and shoulders with high contact area and low air gap thickness. In the abdomen section, a more air permeable fabric (sample-No3) provided better cooling effects. As probably more air is trapped in this section, the higher air permeability contributed to more air exchange and, thus, removal of heat. Of particular interest is the upper arm section. The measurements revealed the best effects for a tight fitting shirt in combination with a high air permeable fabric (sample-No3). We suggest wearing a tight fitting shirt during physical activity in hot and humid conditions. 


\section{Authors' details}

'Department of Testing and Certification, Taiwan Textile Research Institute, New Taipei City, Taiwan. ${ }^{2}$ Swiss Federal Laboratories for Materials Science and Technology, EMPA, St. Gallen, Switzerland. ${ }^{3}$ Department of Business and Planning, Taiwan Textile Research Institute, New Taipei City, Taiwan.

Published: 14 September 2015

\section{References}

1. Havenith $G$, et al: Male and female upper body sweat distribution during running measured with technical absorbents. Eur J Appl Physiol 2008, 104:245-55.

2. Psikuta A, et al: Quantitative evaluation of air gap thickness and contact area between body and garment. Text Res J 2012, 82:1405-1413.

doi:10.1186/2046-7648-4-S1-A134

Cite this article as: Lin et al.: Evaluation of body-mapping shirts design for activities in warm environments. Extreme Physiology \& Medicine 2015 4(Suppl 1):A134.

\section{Submit your next manuscript to BioMed Central} and take full advantage of:

- Convenient online submission

- Thorough peer review

- No space constraints or color figure charges

- Immediate publication on acceptance

- Inclusion in PubMed, CAS, Scopus and Google Scholar

- Research which is freely available for redistribution

Submit your manuscript at www.biomedcentral.com/submit 